\title{
Embodied Interactions with a Sufi Dhikr Ritual: Negotiating Privacy and Transmission of Intangible Cultural Heritage in "Virtual Sama"
}

\author{
Aynur Kadir, Kate Hennessy, Ozge Yalcin, Steve DiPaola \\ Simon Fraser University \\ Canada \\ akadir, hennessy_kate, sdipaola, oyalcin@sfu.ca
}

\begin{abstract}
"Virtual Sama" is an interactive multimedia installation that connects computationally abstracted ethnographic documentation of a Sufi Dhikr ritual with viewers through an artistic artificial intelligence (Al) abstraction process and interactive rhythmic full body movement. In this paper, we describe how the installation is designed to elicit reflection on the implications of transforming intangible heritage into digital heritage through digital documentation and storage, and to encourage exploration of questions around privacy and safeguarding of sensitive cultural practices. Against the context of detailed fieldwork with Uyghur Sufi practitioners in Xinjiang, China, we explore how Al processes and embodied interaction might be mobilised to present alternative representations of anonymity, while drawing attention to the complexities of representation, access and transmission of intangible cultural practices in the digital age.
\end{abstract}

Virtual Sama. Dhikr ritual. Anonymisation. Intangible Cultural Heritage. Embodied Interaction. Privacy.

\section{INTRODUCTION}

The preservation of intangible cultural heritage is dependant on the transmission of intangible cultural practices across generations (UNESCO 2003, Kurin 2004). Digital recording technologies have been seen as helpful in this regard, creating documentary surrogates that can be shared and archived with the intention of facilitating learning and transmission in new forms (Hennessy 2012). However, when intangible cultural practices are endangered by unstable minority-state relations in this case, such as those of Uyghur Sufi practitioners in China - digital documentation of these practices is no longer helpful and may place practitioners at risk. In such a context, the desire for privacy, or anonymity, is in tension with the desire to share intangible cultural practices in service of transmission and preservation. Further, the digital nature of new documentary technologies implicate documentation as digital cultural heritage (Cameron 2007), which raises concerns over ownership and ethical circulation of cultural heritage online (Christen 2009). What are the implications of digital documentation of endangered intangible cultural practices for practitioners? How might interactive media offer possibilities for both drawing attention to these tensions and creating embodied experiences necessary for the transmission of intangible cultural practices? In this paper, we present an interactive installation that encourages physical interaction with computationally abstracted intangible heritage documentation to generate exploration of these questions.

"Virtual Sama" responds directly to world heritage policies of the last decade and the entangled ways in which digital technologies are amplifying ethical and cultural complexities of sharing heritage in virtual space (Christen 2009; Hennessy 2009). For example, while UNESCO categorises world cultural heritage as both tangible cultural heritage and intangible cultural heritage, new technologies are facilitating the rapid documentation of forms and heritage and creating born-digital versions of what we now call "digital cultural heritage" (UNESCO 2003). We are interested in teasing apart the complex relationship between intangible cultural heritage and digital heritage, particularly how we represent these intangible forms of knowledge with digital surrogates when they both have limited materiality, as well as the intertwined ethical considerations and power dynamics associated with dissemination of digital cultural heritage.

The 2003 UNESCO Convention for the Safeguarding of the Intangible Cultural Heritage 
gives us a clear definition of what intangible cultural heritage $(\mathrm{ICH})$ is and articulates the process of "safeguarding" it for the future generations. In Article 2, the definition of $\mathrm{ICH}$ is given as the "the practices, representations, expressions, knowledge, skills - as well as the instruments, objects, artefacts and cultural spaces associated therewith - that communities, groups and, in some cases, individuals recognize as part of their cultural heritage. This intangible cultural heritage, transmitted from generation to generation, is constantly recreated by communities and groups in response to their environment, their interaction with nature and their history, and provides them with a sense of identity and continuity, thus promoting respect for cultural diversity and human creativity. (p.2)". As a living form of heritage, $\mathrm{ICH}$ is dynamic and constantly evolving.

As Richard Kurin points out, responding to the Convention is an ongoing process, since the question of how to facilitate continuity of intangible tradition and knowledge effectively is one of the key points that all cultural organisations will have to consider (Kurin 2004, 2007). This is a crucial time when curators are struggling to represent and share intangible cultural heritage in public museums (Kurin 2004). The project Peləw'k' ${ }^{w}$ Belongings, for example, responds to the tension between the fragmentation of tangible and intangible heritage through the use of an interactive tangible tabletop interface (Muntean et al. 2015).

Safeguarding practices that are facilitated by new visual and digital media technologies raise important questions and concerns around the digital archiving of documents from the field and the complex relationship between these documents, researchers and original communities. Tensions arise because different stakeholders have a range of different objectives and aspirations regarding cultural heritage, whether analog or digital. Legal and ethical debates around fundamental tensions between sharing and privacy are becoming ever more complicated due to digital circulation of cultural heritage (Brown 2003, Hennessy 2009, Anderson \& Christen, 2013). Ethical and practical considerations involved in building access models for digital archives are constantly caught in between the conflicting demands of "open access and privacy" and "free access or appropriate access." (Lessig 2004, Christen 2012).

This heritage and technological context leads us to the question: How might $\mathrm{ICH}$ be transmitted through an interactive experience while encouraging reflection on the different tension between privacy and sharing in digital space?

\section{THE CONCEPT}

"Virtual Sama" is an interactive multimedia installation that connects computationally abstracted documentation of a Sufi Dhikr ritual with viewers via an artistic artificial intelligence (Al) abstraction process that can be explored through interactive rhythmic full body movement. The concept for this installation emerged through interdisciplinary engagements between students and faculty at the School of Interactive Arts and Technology at Simon Fraser University. Aynur Kadir is a Uyghur PhD candidate researching ethical approaches to the archiving and safeguarding of minority ethnic groups oral traditions in the Xinjiang region. She and media anthropologist Kate Hennessy have been exploring possibilities for representing endangered cultural heritage in ways that support transmission and persistence of cultural traditions. Concerned about privacy and anonymity of participants, yet cognisant of participants' desires to share their intangible heritage, they worked with cognitive/computer scientist and artist Steve DiPaola and PhD student Ozge Yalcin and then team's computational abstraction techniques they have been developing to anonymise participants while creating possibilities for embodied engagements with the digital documentation.

In prior research, we have raised questions about utilising new technologies in the field of anthropology: What happens when ethnographic works are made with electronic media or when they are interactive? Are some methodologies better suited to addressing the new ontological conditions of emerging digital-material research tools? (Hennessy et al. 2015) In this case, we wonder how Al painterly abstraction processes might be mobilised to present alternative representations of anonymity, while drawing attention to the complexities of representation in the digital age?

This installation uses $\mathrm{Al}$ processes at different levels of artful abstraction (see figures 1,2 and 3) that both anonymise participants and create dynamic layers of generated visuals, which in our full system can be interactively explored through movement. We are interested in the notion that these different levels of perceptual abstraction might be able to explore or retain the 'spirit' of the Sufi Dhikr ritual, while anonymising the participants in the ritual. At the same time, the interactive element of the installation invites viewers to engage in the kind of embodied movement that the transmission of knowledge and practice of the ritual would require. While the experience of the original ritual is not reproducible through digital documentation alone, "Virtual Sama" aims to create an embodied sensorial exploratory experience 
derived from documentation of an endangered religious practice.

With this work, we aim to elicit reflection on the implications of transforming intangible heritage into digital heritage through digital documentation and storage. When intangible cultural heritage becomes digital heritage, it becomes entangled in ideological and technical systems that prioritise access over privacy (UNESCO 2003, Cameron 2007). To this end, we use our research into digital emotive painterly abstraction techniques which use Al techniques of Genetic Programming and Deep Learning Neural Networks (DiPaola \& McCaig 2016) to draw attention to possibilities for access, remix, and appropriation that cloud computing and Internet-based storage might support. We also ask how such computational abstraction might facilitate a representation of anonymity that could allow sensitive documentation of intangible heritage to be circulated to support its transmission and to acknowledge its persistence in contemporary life.

Versions of this project have also been shown to Sufi practitioners in Xinjiang who are represented in the installation. Feedback was provided on levels of abstraction and general aesthetics, as an initial participatory phase of this project, which we hope to develop further in the future. In the following section, one of us (Aynur Kadir) provides necessary context for understanding how the Dhikr ceremony came to be filmed, and the predicament of Sufi Dhikr in Xinjiang today.

\section{THE CONTEXT}

\subsection{Fieldwork Vignette: Xinjiang, China, 2015}

I [Aynur Kadir] arrived on December 18, 2015 in Qaraghoja, near Turpan, Xinjiang, a remote northwestern part of China. Sufi faithful from miles away came on foot, by donkey cart, or by motorcycle or car to Qasim Caliph's house, a well known Sufi leader, in remembrance of the day he died 22 years ago. They are his followers and students, who revere their spiritual guide. After filming several Dhikr events of both men and women at Qasim Caliph's shrine, at the Khaniqa (Sufi Lodge) and his house, the strong rhythmic sound of Dhikr continued to resonate in my mind.

Dhikr is a rhythmic chanting, meditation, devotion, and healing ritual that is common in many Sufi Muslim communities around the world. In Uyghur it also called Helqe-Sohbet (literally "circling and talking") or Sama (similar in Turkish Persian and Arabic). It has been an important means of expressing the love for Allah among the Sufis, marked often by powerful trances and mystical experiences (Harris 2008). It covers a wide range of activities ranging from chanting and poetic recitation to storytelling and Sufi dancing (whirling). The ritual, which typically lasts between two to five hours, usually ends with a climax - the shedding of the holy tears that are thought to be capable of extinguishing the hell fire and wash away the sin.

The day after I arrived in Qaraghoja, dozens of women stayed back to help the family in cleaning up at Qasim Caliph's shrine. I showed these women the film I had recorded at this very house six years ago, during which many of them were present. They became deeply emotional, confirming the value of these recordings in their community.

I sat by an elderly Büwi (female Sufi disciple) to conduct an interview about dhikr. After answering all my questions very carefully, she asked me: "Daughter, do you believe in it?" I was tongue-tied. I have a deep respect, understanding and attachment to Sufi traditions. I have been in many Sufi shrines, Dhikr ceremonies, and sacred rituals and witnessed so many "holy tears". However, I am a scholar who is trained as a Marxist in China, and in the critical Western academic tradition and do not particularly identify myself as a Sufi. She saw my confused face and continued the conversation to break the awkward silence. "Daughter, I want to teach you how to do Dhikr, please follow me". I knelt as she demonstrated to me and she continued "touch your tongue to your upper palate, close your eyes, and repeatedly say "Al-la-hu"; focus on your heart when you say "Al", focus on your tongue when you day "la", and focus on your brain when you say "hu". You don't have to vocalise the word, it echoes in your mind; move along your body to the rhythm. You will feel your spirit circling your body and cleaning your soul. You will feel the calmness in your heart, and you can see the clarity in your brain".

While I have documented this ritual in its entirety, the video footage cannot capture how deeply affected I was, and the spiritual connection I felt with these women. On my way back, I looked out my bus window at the Xinjiang landscape passing by, and wondered: How could my camera ever capture the sensorial, embodied dimension of this religious practice? What are my responsibilities to archive and preserve these documentary media? How might I contribute to the safeguarding and transmission of this intangible cultural heritage while being respectful to the wishes of my community elders?

\subsection{Sufism among Uyghurs}

Sufism scholar Annemarie Schimmel has unpacked the transnational phenomenon of Sufism among the Persian, Turkish, and Indo-Muslims based on her long-term fieldwork and literature reviews in 
different languages. She explains how mysticism in Sufism is love of the absolute, and how a Sufi meditates their absolute love of Allah no matter what language they speak (Schimmel 1975). Sufism has been a very influential and active religious tradition in Central Asia, including Uyghurs in Xinjiang, yet the fate and reputation of Sufism have been negative (Bellér-Hann 2007). Sufi activities have been regarded as "illegal" by government officials and thus banned in many areas. Islamic fundamentalism in this area also has criticised Sufi rituals and related activities as heretical. The cultural-religious spaces, in which these Sufi groups have long met, along with the actual religious practices associated with them, are quickly disappearing (Dawut 2009). In response, a number of Sufi sisterhoods and brotherhoods have begun to meet and perform their rituals underground. During my collaborative ethnographic fieldwork with Xinjiang Folklore Research Center, I have focused on recording local Sufi knowledge as well as the songs and rituals. As one of the Sufi elders with whom I spoke said:

\begin{abstract}
"We did nothing wrong but meditate, express our love to Allah and be peaceful, yet Uyghur elites despise us, Islamic fundamentalists hate us as they claim Islam can't have music and state authorities ignore us and ban our gathering. This is a 500 year tradition, we want our kids learn what we do and outsiders understand why we do this."
\end{abstract}

The mis-representation of Sufism among Uyghur community has multiple layers of complexity, influential Marxist Uyghur intellectuals critical of Sufism and the anti-Sufism rhetoric is a growing trend and created this power struggle between Uyghur elites and Sufis (Dawut 2016). In addition, recent state policy of "eradicating religious extremism" and "stability", which are not in favour of large-scale gatherings, especially religious ones, create a very difficult situation for continuity of Sufi cultural practitioners. In this complex situation that stated in earlier section Sufi elders express the hope and desire to save this tradition from dying.

\section{COMPUTATIONAL ABSTRACTION}

This section describes how we have used computational abstraction and 3D movement detection systems to explore the potential for creating anonymity and supporting embodiment of intangible cultural practices.

\subsection{Anonymity}

The tension between the possibility of misinformation and the need to protect the vulnerable groups is an active research topic in social and human sciences (Wiles et. al. 2012, Pauwels 2008, Prosser 2000). The existing guidelines for anonymising visual data by the International Visual Sociology Association (Papademas \& the IVSA 2009) is insufficient and too broad to be applied (Wiles et al. 2008), especially in our specific narrative case. In our case study, the significance of representing the essence of the rituals in order to transmit the knowledge practice becomes more prominent as the society is already struggling with misrepresentation. Blacking out, blurring or pixelation of the face are standard de-identification techniques that completely isolate and alter the face image. These techniques and their variations have been successfully used in deidentification of video surveillance data (Newton et al. 2005). Although these approaches are very effective on assuring the privacy of the individuals, it paves the way for altering the integrity of the captured image and potentially victimising the subject.

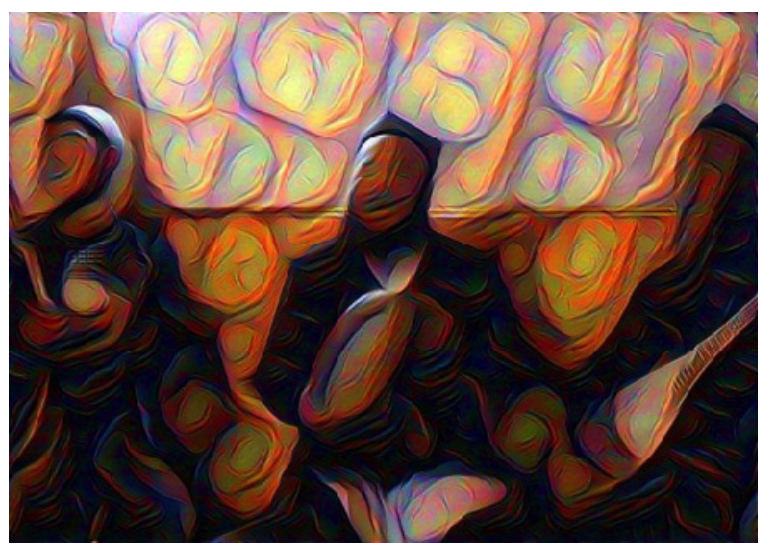

Figure 1: Video Still, Virtual Sama, 2017

Faces are considered to be the primary system for showing and understanding emotions (Mayer et al. 1990), which appears to be mostly an innate capability in humans (Ekman \& Friesen 1971, Ekman \& Oster 1979). However, faces are not the only source for arousal in visual pieces; aesthetics may also trigger emotions in an individual. In this installation, we attempt to use art to fill the missing emotional link created by the anonymisation process. The goal of the use of the computational abstraction system is to protect the privacy of vulnerable cultural heritage practitioners while communicating the essence of their cultural practice.

\subsection{Embodied Interaction}

Practice theory defines action as a basis for social meaning making process, a means for constructing a shared knowledge (Reckwitz 2002). In this view, the body is more than an instrument but an agent that performs actions in the world. The body is viewed as the subject of culture, as a grounding for culture to emerge (Csordas 1990) via collective interaction. Embodiment as an "indeterminate 
methodological field defined by perceptual experience and mode of presence and engagement in the world" (Csordas 1994, p. 12), becomes the essential part of transmitting social practices.

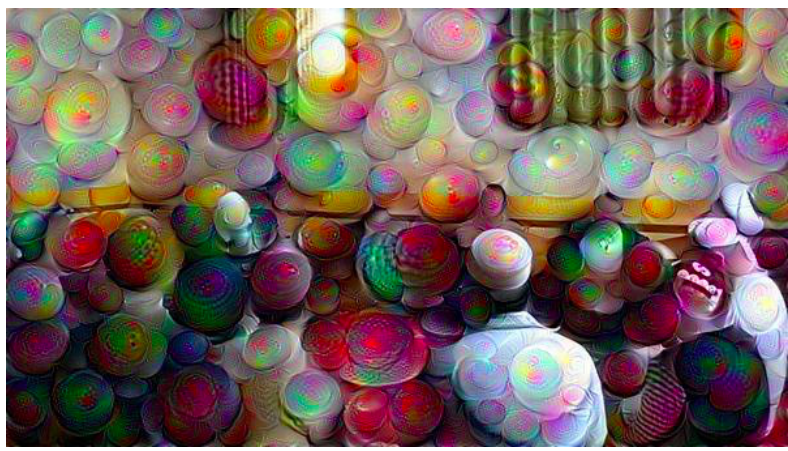

Figure 2: Video Still, Virtual Sama, 2017.

As the Sufi Dhikr ritual is passed on across generations with embodied collective interactive experience, situated participation is an important part of understanding this practice. Bodily actions such as breathing, rhythmic body movement and chanting can be acquired through direct observations. Learning through direct experience is widely driven by reinforcements, rewarding and punishing consequences that follow the action (Bandura \& Walters 1977). Therefore, feedback is essential in the negotiation of meaning through participation and reification (Wenger 1998).

In this installation, we aim to create a parallel embodied experience for the audience. As a result, the artwork generated from the anonymisation process is presented as an embodied interactive art piece. Interaction in art, transforms the audience to have an essential role in the making of the art as a participant (Candy \& Edmonds 2002). This interactive installation guides the audience to play a participatory role in the transforming of the artwork through the perceptually related layers of abstraction. Audience members are encouraged to model the rhythmic body movement that is shown in the ritual. The real-time feedback from the movement tracking technology can create an immediate situatedness and endorse the learning process. The juxtaposition of clear acoustic chanting documented from past rituals and abstract visuals with embodied physical movement will convey sensory experience to participants. The interactive explores both solo (1 person) as well as collective interaction in the form of synchronised full body interaction (group participants up to four) allowing for a single or collective experience.

\subsection{Technical Process}

The project applies our research into computational painterly abstraction including $\mathrm{Al}$ techniques of
Genetic Programming and Deep Learning Neural Networks (DNN) (DiPaola 2014a, 2014b, DiPaola \& McCaig 2016). This work uses Al techniques to learn cognitive creative art practice via analysis of historical art databases as well as encoding knowledge of art practice. While many $\mathrm{Al}$ art based systems of this type use a more template based approach, which limits the system to make one style or transfer style from a painting to a source, our system uses a more open perceptual based approach based on cognitive theories of human creativity (Salevati \& DiPaola 2015, Salevati et al. 2016). For instance one such cognitive creativity based method in our system is conceptual blending.

Conceptual Blending is a proposed cognitive mechanism that allows for the creation of new concepts by integrating pre-existing conceptual spaces (Fauconnier \& Turner 1988). Al DNNs have been previously used to apply the idea of Conceptual Blending to visuals in order to aid creativity (McCaig et al. 2016). They generate a synthesis of visuals by combining lower level visual qualities such as images, shapes and textures with the higher-level concepts. The low-level qualities are extracted from a guide image and used to change the features of the source image. The layers of the network allow the production of blends with varying levels of intensity. With each layer of the network these low level characteristics of the guide image are allowed to dominate the source image.

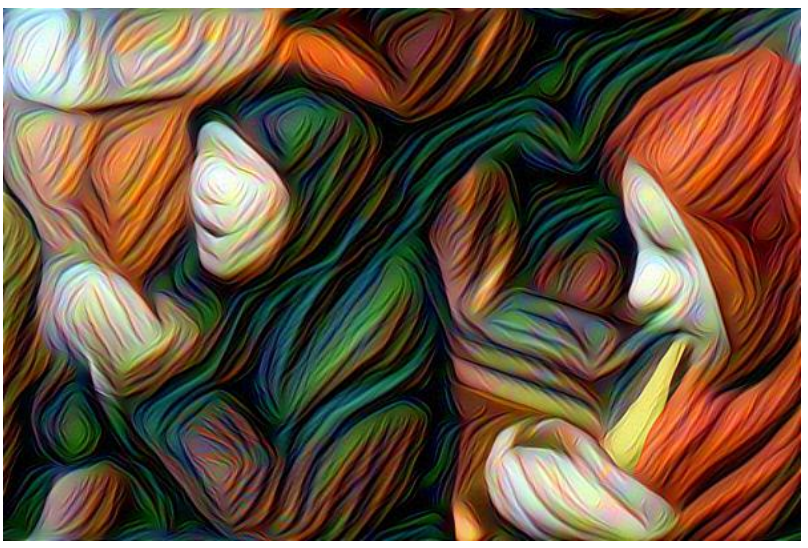

Figure 3: Video Still, Virtual Sama, 2017.

Our DNN Al abstraction process makes explicit autonomous evaluations of the novelty and value of the source imagery as it abstracts. How this Al creative process works can be viewed as important for creativity, for example, Jennings (2010) includes such autonomous evaluation as a necessary condition for creative autonomy. In terms of novelty, the abstraction system creatively isolates and maximises subsets of the visual features evoked by the source video, resulting in the emergence and/or enhancement of certain aspect 
image qualities (or whole levels of abstraction) at the expense of other qualities. This process can be construed as the computation of one or more aesthetic value metrics. It bears a resemblance to neuroaesthetic principles of art, such as Zeki's (2001) notions of stimulating discrete portions of visual processing and translating the brain's abstractions onto the canvas. In this way the abstraction system can bring out shapes and unintentional objects in ways associated with the human creative process. This type of system with open ended perceptually valid parameters allow us to author multiple levels of abstraction in ways that can be somewhat synced up (in an artful way) to the notion of spirituality in the Sufi Dhikr ritual, while protecting participants' privacy.

Within our authoring flow, the Al abstraction process uses images of natural sources such as tree bark, bees; cultural elements such as a Uyghur shrine flag, embroidery and traditional Uyghur motifs as 'guide images' in order to compare how various guide images have an impact on the aesthetics. The source of each frame image is extracted from the documented ethnographic videos and fed to our system to obtain the output images from different perceptual abstraction levels of the Al neural network. The resulting imagery was then shown to members of the community depicted in the videos in order to get their feedback and consent on the process. At this stage, the appropriate abstraction levels for anonymisation were agreed upon.

The finalised set of imagery consists of multiple video layers of perceptually related visual blends processed from the source video documentation. Using a Kinect v.2 motion sensor connected to Unity interaction software, which is then displayed either on a large monitor (see Figure 4), projection system or head mounted display. This allowed the participants to interactively communicate (e.g. move through abstraction layers) with the perceptual video layers via their rhythmic body movement.

We explored multiple movement patterns with single or up to four users and decided to use a backward and forward rhythmic leaning motion while sitting in a collective setting in order to resemble the Sama body motion presented in the videos. Figure 4 (right) shows an example of how this motion changes and attains a certain through the abstraction of video layers of the installation. Our system allows us to manage cross dissolving between these perceptually related layers while synchronising with the movements of the participants.
CNN System

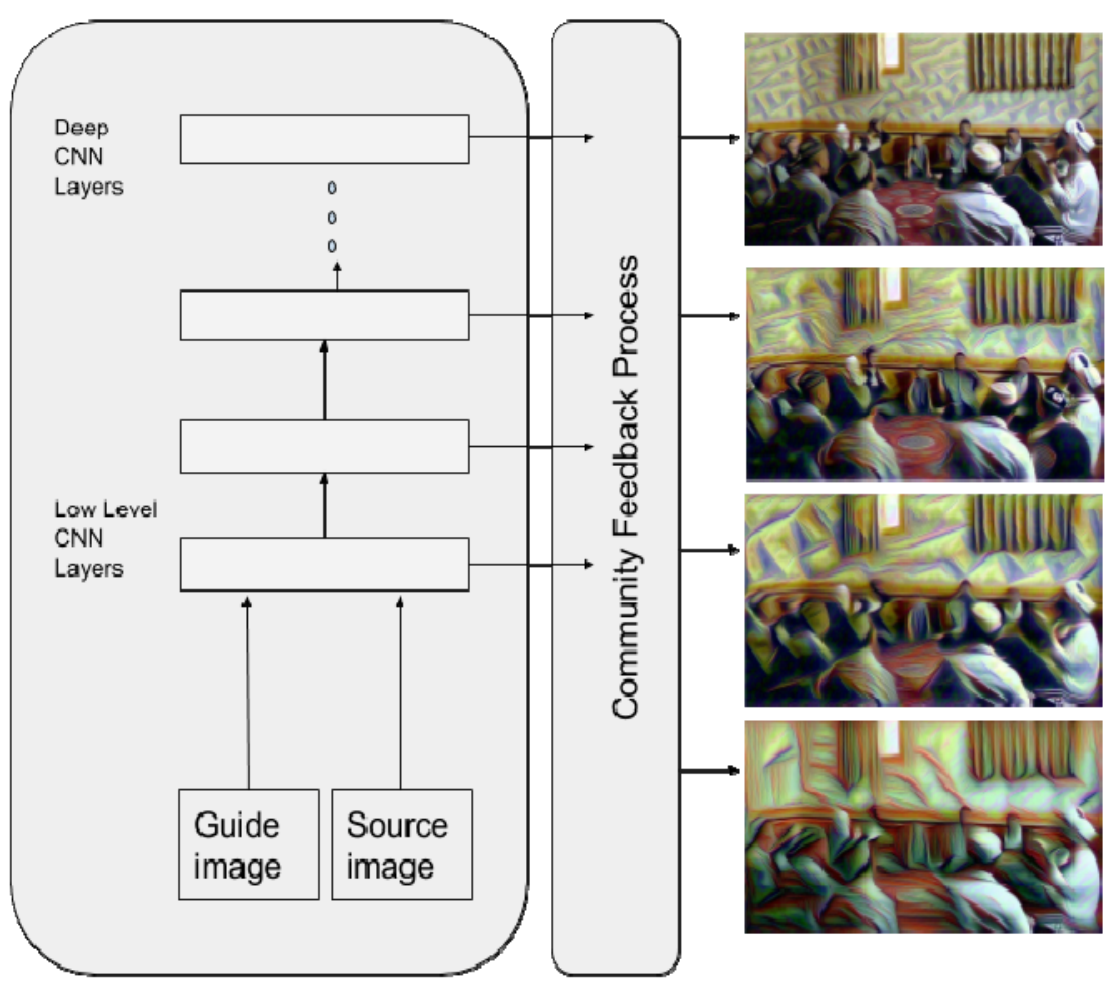

Kinect System

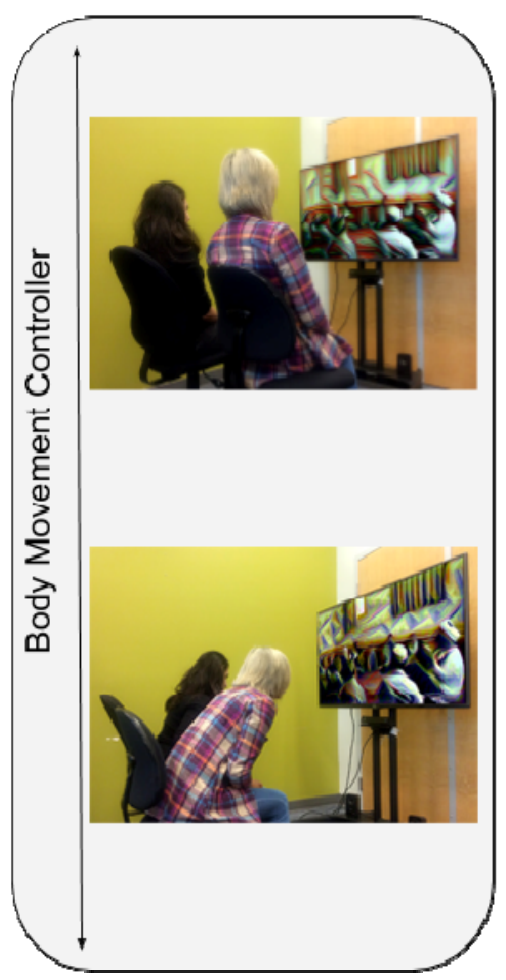

Figure 4: Technical Layers of Virtual Sama. 


\section{CONCLUSION}

"Virtual Sama" is situated to reflect tensions between privacy and transmission of intangible cultural heritage. New knowledge based technologies such as our Al computational abstraction system and motion sensor system offer possibilities for both drawing attention to these tensions and creating embodied experiences necessary for the transmission of intangible cultural practices. This project anonymises this particular ethnographic recording of a Dhikr ritual while exploring the potential for computational abstraction and embodied interaction to communicate the spirit of the original event. How, we ask, might artful Al techniques and full body interaction raise awareness of the need for the safeguarding intangible cultural heritage? How do artful $\mathrm{Al}$ techniques in this instance draw attention to the implication of intangible cultural heritage in the digital heritage complex and the protection of individual privacy?

Our project further explores the use of interactive body tracking technology to promote the cultural learning process by encouraging embodied interaction. The computational abstraction system may provide one way to create an alternative representation of a digital recording of an endangered and sensitive intangible cultural practice.

However, further investigation is required to better understand the balance between achieving anonymity and providing access to digital representations of Sufi Dhikr in service of transmission of intangible cultural heritage. Does computationally abstracted heritage documentation facilitate the transmission of cultural practices? Does the interactive element requiring physical interaction with the installation facilitate the transmission of cultural practices? This installation does not answer these questions but invites viewers to contemplate their potential and engage critically with digital heritage and its complexities.

Further work is also required to advance the participatory aspect of the project - working with the cultural practitioners to collaboratively develop artful Al techniques to anonymise and computationally abstract their own representations. We aim to develop this aspect of the work in the future, building on our initial consultations with practitioners included in the documentation in the installation.

\section{ACKNOWLEDGMENTS}

We acknowledge all community elders, Sufi practitioners who actively participated in this project. Special thanks to Rahile Dawut and $\mathrm{Mu}$ Qian for supporting the documentation process.

\section{REFERENCES}

Anderson, J. and Christen, K. (2013) 'Chuck a Copyright on it': Dilemmas of Digital Return and the Possibilities for Traditional Knowledge Licenses and Labels. Museum Anthropology Review, 7(1-2), pp. 105-126.

Bandura, A. and Walters, R. H. (1977) Social learning theory. Prentice Hall. Englewood Cliffs, NJ

Bellér-Hann, I. (ed.) (2007) Situating the Uyghurs between China and Central Asia. Ashgate Publishing. Farnham

Brown, M. F. (2003) Who Owns Native Culture? Harvard UP. Cambridge, MA.

Candy, L. and Edmonds, E. (2002) Interaction in art and technology. Crossings: Electronic Journal of Art and Technology, 2(1).

Cameron, F. and Kenderdine, S. (eds.) (2007) Theorizing digital cultural heritage: A critical discourse. MIT Press. Cambridge, MA.

Christen, K. (2009) Access and Accountability: The Ecology of Information Sharing in the Digital Age. Anthropology News, 50(4), pp. 4-5.

Christen, K. (2012) Does information really want to be free? Indigenous knowledge systems and the question of openness. International Journal of Communication, 6, pp. 2870-2893.

Csordas, T. J. (1990) Embodiment as a Paradigm for Anthropology. Ethos, 18(1), pp. 5-47.

Csordas, T. J. (1994) Embodiment and experience: The existential ground of culture and self (Vol. 2). Cambridge UP. Cambridge.

Dawut, R. (2009) Shrine pilgrimage among the Uighurs. Silk Road, 6(2), pp. 56-67.

Dawut . R (2016) Ordam Mazar: A Meeting Place for Different Practices and Belief Systems in Culturally Diverse Xinjiang In Bellér-Hann, I., Schlyter, B. N. and Sugawara, J. (eds) Kashgar revisited: Uyghur studies in memory of Ambassador Gunnar Jarring, Brill. . Leiden.

DiPaola S. (2014a) Using a Contextual Focus Model for an Automatic Creativity Algorithm to Generate Art Work, Procedia Computer Science., 41, pp. 212-219.

DiPaola S. (2014b) Computer Modelling Fine Art Painting using a Cognitive Correlative Heuristics Approach, Proc: Biologically Inspired Cognitive Architectures. MIT Press. Boston, MA.

DiPaola S., McCaig R., (2016) Using Artificial Intelligence Techniques to Emulate the Creativity of 
a Portrait Painter. Electronic Visualisation and the Arts, British Computer Society, London.

Ekman, P. and Friesen, W. V. (1971) Constants across cultures in the face and emotion. Journal of personality and social psychology, 17(2), p.124.

Ekman, P. and Oster, H. (1979) Facial expressions of emotion. Annual review of psychology, 30(1), pp. 527-554.

Fauconnier, G. and Turner, M. (1998) Conceptual integration networks. Cognitive Science, 22(2), pp. 133-187.

Hennessy, K. (2009) Virtual Repatriation and Digital Cultural Heritage: The Ethics of Managing Online Collections. Anthropology News, 50(4), pp. 5-6.

Hennessy, K. (2012) Cultural heritage on the web: Applied digital visual anthropology and local cultural property rights discourse. International Journal of Cultural Property, 19(3), pp. 345-369.

Hennessy, K., Fortin, C., Kadir, A., Muntean, R., and Ward, R. (2015) Producing New Media Ethnographies with a Multi-Sited Approach. Proceedings of the 21st International Symposium on Electronic Art.

Harris, R. A. (2008) The Making of a Musical Canon in Chinese Central Asia: The Uyghur Twelve Muqam. Ashgate Publishing. Farnham.

Jennings, K. E. 2010. Developing creativity: Artificial barriers in artificial intelligence. Minds and Machines, 20(4), pp. 489-501.

Kurin, R. (2004) Safeguarding Intangible Cultural Heritage in the 2003 UNESCO Convention: a critical appraisal. Museum International, 56(1-2), pp. 66-77

Kurin, R. (2007) Safeguarding intangible cultural heritage: Key factors in implementing the 2003 Convention. International Journal of Intangible Heritage, 2, pp. 9-20.

Lessig, L. (2004) Free culture: How big media uses technology and the law to lock down culture and control creativity. The Penguin Press, London

Mayer, J. D., DiPaolo, M., and Salovey, P. (1990) Perceiving affective content in ambiguous visual stimuli: A component of emotional intelligence. Journal of personality assessment, 54(3-4), pp. 772-781.

McCaig, R., DiPaola, S., and Gabora, L. (2016) Deep Convolutional Networks as Models of Generalization and Blending within Visual Creativity, Proc: International Conference on Computational Creativity.

Muntean, R., Hennessy, K., Antle, A., Rowley, S., Wilson, J., Matkin, B., Eckersley, R., Tan, P., and
Wakkary, R. (2015) Belongings: a tangible interface for intangible cultural heritage. In Proc: Electronic Visualisation and the Arts (pp. 360-366). British Computer Society.

Newton, E. M., Sweeney, L., and Malin, B. (2005) Preserving privacy by de-identifying face images. IEEE transactions on Knowledge and Data Engineering, 17(2), pp. 232-243.

Papademas, D. and The International Visual Sociology Association (2009) IVSA code of research ethics and guidelines. Visual Studies, 24, pp. 250-257.

Pauwels, L. (2008) Taking and using. Visual Communication Quarterly, 15, pp. 243-257.

Prosser, J. (2000) The moral maze of image ethics. In H. Simons \& R. Usher (eds.), Situated ethics in visual research. London: Routledge. pp. 116-132.

Reckwitz, A. (2002) Toward a theory of social practices: A development in culturalist theorizing. European journal of social theory, 5(2), pp. 243263.

Salevati S, DiPaola S, (2015) "A Creative Artificial Intelligence System to Investigate User Experience, Affect, Emotion and Creativity", Proc: Electronic Visualisation and the Arts, British Computer Society, London.

Salevati S., DiPaola S., Carlson K. (2016) Movement Awareness through Emotion Based Aesthetic Visualization, Proc: Electronic Visualisation and the Arts, British Computer Society, London.

Schimmel, A. (1975) Mystical dimensions of Islam. Univ of North Carolina Press. Chapel Hill, NC

UNESCO (2003) Convention for the Safeguarding of the Intangible Cultural Heritage.

UNESCO (2003) Charter on the Preservation of Digital Heritage.

Wenger, E. (1998) Communities of practice: Learning, meaning, and identity. Cambridge University Press, Cambridge, UK.

Wiles, R., Prosser, J., Bagnoli, A., Clark, A., Davies, K., Holland, S., and Renold, E. (2008) Visual Ethics: Ethical Issues in Visual Research. Southampton: ESRC National Centre for Research Methods. http://eprints.ncrm.ac.uk/421/

Wiles, R., Coffey, A., Robinson, J., and Heath, S. (2012) Anonymisation and visual images: Issues of respect, 'voice' and protection. International Journal of Social Research Methodology, 15, pp. 41-53.

Zeki, S. 2001. Essays on science and society: Artistic creativity and the brain. Science, 293(5527), pp. 51-52. 